\title{
Optimal Power Supply Frequency for Wastewater Treatment by Using Underwater Plasma Discharges
}

\author{
Tassanai SUPANARAPAN and Boonruang MARUNGSRI ${ }^{*}$ \\ School of Electrical Engineering, Suranaree University of Technology, Nakhon Ratchasima, Thailand \\ ${ }^{*}$ Corresponding author
}

\begin{abstract}
This paper presents the development of an underwater plasma for wastewater treatment. A treatment reactor made of acrylic with multiple stainless-steel rods as the cathode electrode and stainless-steel plate as the ground was used. To find the suitable frequency for treatment, $25 \mathrm{kV}$ pulse high voltage with the adjustable frequency of $20 \mathrm{kHz}, 40 \mathrm{kHz}$, and 60 $\mathrm{kHz}$, was applied to the cathode electrode inside the treatment reactor for generating plasma discharge. The quality of treatment process was evaluated by standard levels of the Biological Oxygen Demand (BOD) and the Chemical Oxygen Demand (COD). By the treatment results, it was found that $25 \mathrm{kV}$ pulse high voltage with $20 \mathrm{kHz}$ frequency was more suitable for wastewater treatment when compared with the other two frequencies due to the faster reduction in COD and BOD values were measured.
\end{abstract}

Keywords-wastewater treatment; wastewater; COD; BOD; underwater plasma discharge

\section{INTRODUCTION}

Presently, water pollution has become an interruption of the environment in the broad boundary given the agricultural and industrial factory. That is important to protect the environment for future arrangements it should start today. The objective of this research is a proposed case study of power frequency effect of prototype underwater plasma for treat wastewater.

Recently, the remnant of a chemical compound in used water from industry factory and agriculture area has mostly reported affecting human health. The Oxidation Pond method is a famous method for wastewater treatment. However, this technique required a long time for treatment and generated the terrible smells from H2S in a treatment process. Many researchers have been researched the decomposition of organic materials in wastewater, and the treatment techniques were investigated. Such as arc discharge [1], microwave discharge [2], high repetition discharge plasma [3, surface plasma [4] and gas pulse discharge [5]. Up to now, the process for wastewater treatment is widely developed. However, it is not enough to treat a lot of wastewater from many activities of a human. Recently, electrical discharge treatment technique by applying a high voltage in the liquid phase was widely interested. Many technologies have been researched to degrade contaminants. Such as non-thermal plasma was investigated by Sun et al. [6]. Corona streamer discharge was studied by San et al. [7], Sato et al. [8], and Joshi et al. [9]. Spark discharge was introduced by Sun et al. [10]. Underwater plasma is a new trend for decomposing organic materials in water [11].
The effect of supply frequency for wastewater treatment by using underwater plasma was studied in this paper. Three levels of power supply frequency, i.e., $20 \mathrm{kHz}, 40 \mathrm{kHz}$, and $60 \mathrm{kHz}$ were applied to the water treatment reactor for treated wastewater at the ambient temperature.

\section{EXPERIMENTAL}

In the experimental, a $25 \mathrm{kV}$ high voltage pulse power supply with the variable frequencies of $20 \mathrm{kHz}$ to $60 \mathrm{kHz}$ converted from $220 \mathrm{Vac}, 50 \mathrm{~Hz}$ was used as a power source. The treatment process was implemented under the test conditions for underwater plasma discharges at ambient temperature.

\section{A. Wastewater Sample}

Wastewater sampling was collected from a wastewater storage pond in the Suranaree University of Technology as shown in Fig. I. The wastewater sampling was taken during daytimes, and it was kept in a plastic bottle as shown in Fig. II. The COD and the BOD levels of the wastewater sampling were measured before treatment.

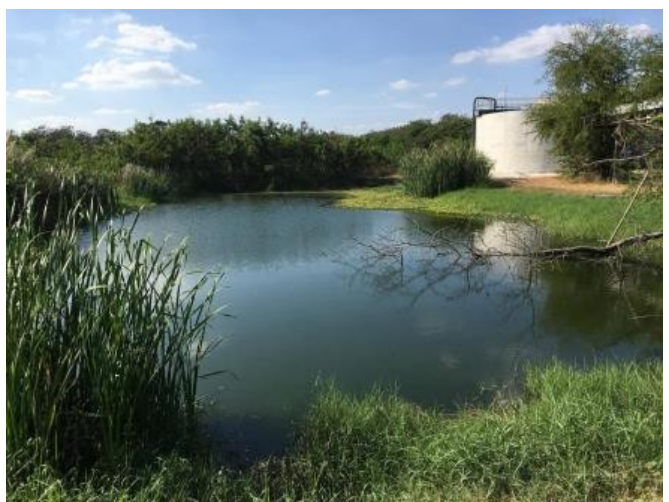

FIGURE I. WASTEWATER STORAGE POND 


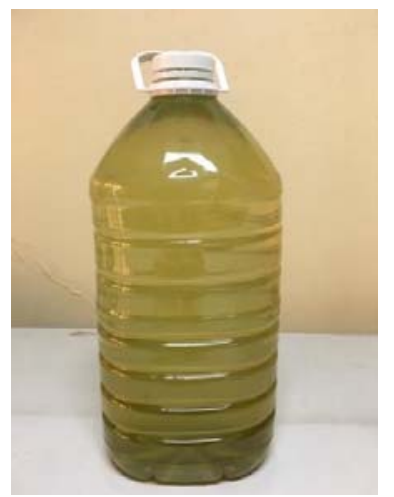

FIGURE II. THE WASTEWATER SAMPLE

\section{B. Treatment Chamber}

The treatment reactor for wastewater treatment was made of a cylinder thermoplastic with $140 \mathrm{~mm}$ height, $93 \mathrm{~mm}$ diameter and $15 \mathrm{~mm}$ thickness. The experimental arrangement is shown in Fig. III. High voltage electrode and grounding electrode were installed in the intramural space of the treatment chamber to generate plasma discharge. A high voltage electrode is a group of 16 stainless steel pins attached to the plate. The dimension of an $\mathrm{HV}$ electrode pin is $20 \mathrm{~mm}$ diameter, $38 \mathrm{~mm}$ high and $30^{\circ}$ curvature. HV electrode installed at the upper part in the intramural space of the treatment chamber while grounding electrode installed at the bottom portion. Holes were drilled at the grounding plate for injecting the compressed air to generating small air bubbles. The gap between the HV electrode and the grounding electrode is $70 \mathrm{~mm}$.

Ground Electrode

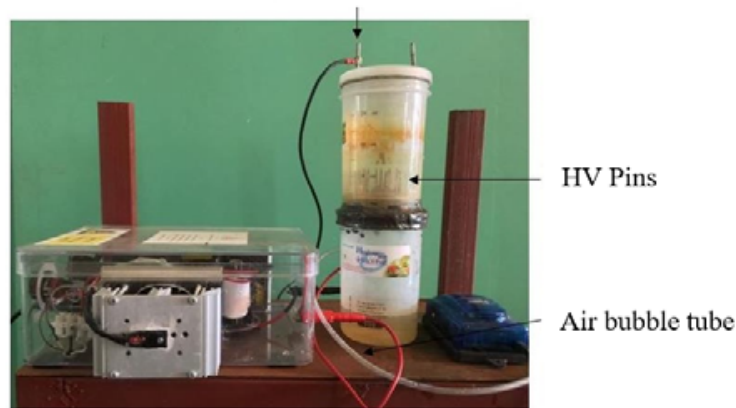

FIGURE III. TREATMENT CHAMBER AND THE EXPERIMENTAL ARRANGEMENT

Wastewater was filled in the treatment chamber for treatment, and the HV electrode was dipped in wastewater. Compressed air was pumped and was injected into the treatment process. The treatment process was conducted until the COD, and the BOD levels belong to the standard of the Pollution Control Department, Ministry of Natural Resources and Environment of Thailand. The standard level for the COD is 120 $-400 \mathrm{mg} / \mathrm{l}$ and the standard level for the COD is $20-60 \mathrm{mg} / \mathrm{l}$.

A $25 \mathrm{kV}$ high voltage pulse with adjustable frequency power supply was used as the power supply in this study. Three levels of frequency were used, i.e. $20 \mathrm{kHz}, 40 \mathrm{kHz}$, and $60 \mathrm{kHz}$, respectively. The power supply started with $220 \mathrm{Vac} 50 \mathrm{~Hz}$.
Then a 220 Vac $50 \mathrm{~Hz}$ was rectified into 12 Vdc and 24 Vdc. A 12 Vdc was used to supply a PWM Generator to generate the control signal for the switching Power MOSFET (IRFP460) operation. A 24 Vdc was used to supply the Flyback transformer to generating $25 \mathrm{kV}$ high voltage pulse.

\section{Test Conditions}

The conditions for wastewater treatment process are shown in Table I. The experiment was performed under the same electrical stress magnitude at ambient temperature. A $25 \mathrm{kV}$ high voltage pulse was continuously applied during the treatment process.

TABLE I. TEST CONDITIONS

\begin{tabular}{|c|c|}
\hline Voltage & $25 \mathrm{kV}$ pulse \\
\hline Frequency & $20 \mathrm{kHz}, 40 \mathrm{kHz}, 60 \mathrm{kHz}$ \\
\hline Temperature & Ambient \\
\hline Period & Until COD and BOD value is in range \\
\hline
\end{tabular}

\section{RESULTS AND DISCUSSION}

Before treatment wastewater, the COD and the BOD of wastewater were measured. The COD and the BOD levels at $440 \mathrm{mg} / \mathrm{l}$ and $45 \mathrm{mg} / \mathrm{l}$ were measured from the wastewater sample, respectively. Wastewater was treated until the COD, and the BOD levels reach the standard of the Pollution Control Department, Ministry of Natural Resources and Environment of Thailand. These levels are the quality parameters for treated water before disposed into the environment. Decreasing in the COD level along the treatment time is shown in Fig. 4. The role of power supply frequency can be seen from the experimental results. Faster reduction in the COD level was obtained when a $25 \mathrm{kV}$ high voltage pulse with the frequency of $20 \mathrm{kHz}$ was subjected to the treatment chamber compared with the frequency of $40 \mathrm{kHz}$ and $60 \mathrm{kHz}$.

As seen in Fig. 4, after 24 hours of treatment, even the same voltage stress magnitude, the more significant reduction of the COD level was obtained from the wastewater sample subjected to a $25 \mathrm{kV}$ high voltage pulse with $20 \mathrm{kHz}$ of frequency. $60 \%$ of the COD reduction was measured while $57.73 \%$ of the COD reduction was measured when subjected to $40 \mathrm{kHz}$ of the frequency and 55\% of the COD reduction was measured when subjected to $40 \mathrm{kHz}$ of the frequency, respectively.

Decreasing in the BOD level along the treatment time is shown in Fig. 5. Similar to the COD, the role of power supply frequency can also be seen from the experimental results. Faster reduction in the COD level was obtained when a $25 \mathrm{kV}$ high voltage pulse with the frequency of $20 \mathrm{kHz}$ was subjected to the treatment chamber comparing with frequencies of $40 \mathrm{kHz}$ and $60 \mathrm{kHz}$.

From Fig. V, after 24 hours of treatment, even the same voltage stress magnitude, the more significant reduction of the BOD level was obtained from the wastewater sample subjected to a $25 \mathrm{kV}$ high voltage pulse with $20 \mathrm{kHz}$ of frequency. $60 \%$ of the BOD reduction was measured while $48.89 \%$ of the BOD reduction was measured when subjected to $40 \mathrm{kHz}$ of the frequency and $40 \%$ of the BOD reduction was measured when 
subjected to $40 \mathrm{kHz}$ of the frequency, respectively. The experimental results confirmed the effectiveness of treatment chamber.

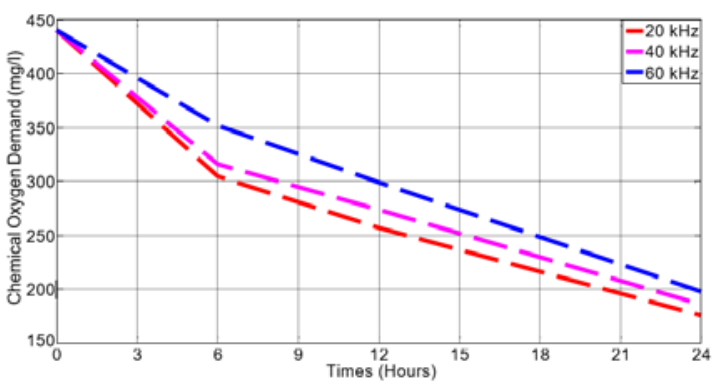

FIGURE IV. THE REDUCTION OF THE COD LEVEL

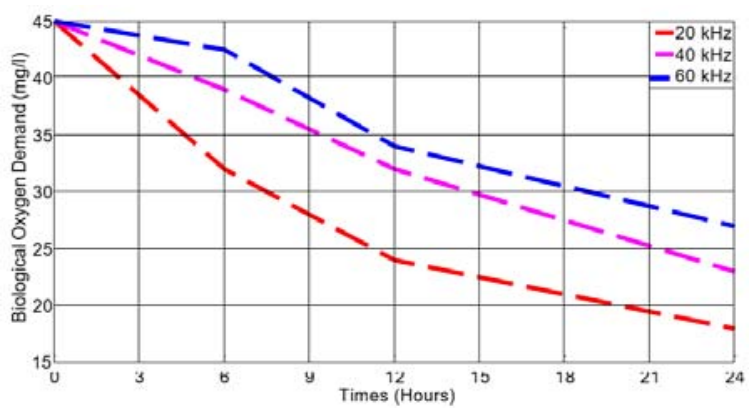

FIGURE V. THE REDUCTION IN THE BOD LEVEL

\section{CONCLUSION}

The prototype of the treatment chamber for treating wastewater by using underwater plasma technique was proposed in this work. Wastewater taken from wastewater storage pond in the Suranaree University of Technology was treated to evaluate the effectiveness of the treatment chamber. A $25 \mathrm{kV}$ high voltage pulse was supplied to the treatment chamber with the frequencies of $20 \mathrm{kHz}, 40 \mathrm{kHz}$, and $60 \mathrm{kHz}$. The COD and BOD were used to confirm the quality of treated water. The treatment process was stopped when the COD and the BOD levels reached the standard of the Pollution Control Department, Ministry of Natural Resources and Environment of Thailand, i.e., 120-400 $\mathrm{mg} / \mathrm{l}$ for the COD and 20-60 $\mathrm{mg} / \mathrm{l}$ for the BOD, respectively. The experimental results showed that shortest treated time was obtained when the treatment chamber subjected to a $25 \mathrm{kV}$ high voltage pulse with the frequencies of $20 \mathrm{kHz}$.

\section{ACKNOWLEDGEMENT}

This work was supported by the High Voltage Laboratory of the Suranaree University of Technology.

\section{REFERENCES}

[1] R. Burlica, R. Grim, K. Shih, D. Balkwill, B. R. Locke, Bacteria Inactivation Using Low Power Pulsed Gliding Arc Discharges with Water Spray, Plasma Processes and Polymers, 2010.

[2] X. Zhao, X. Zhu, Z. Yan, Y. Liu, H. Liu, B. Sun, Optical Study of Active Species Produced by Microwave Discharge in Water, IEEE TRANSACTIONS ON PLASMA SCIENCE, 2006.
[3] K. Kouno, T. Sakugawa, K, Kawamoto, S. Hosseini, S. Katsuki, H. Akiyama, M. Hara, Generation of discharge plasma in water by high repetition rate pulsed power modulator, IEEE Pulsed Power Conference, 2009.

[4] M. Sato, T. Soutome, S. Mii, T. Ohshima, Y. Yamada, Decomposition of Phenol in Water Using Water Surface Plasma in Wetted-wall Reactor, International Journal of Plasma Environmental Science \& Technology, 2007.

[5] Y. Wu, J. Li, G. Li, N. Li, G. Qu, C. Sun, M. Sato, Decomposition of Phenol in Water by Gas Phase Pulse Discharge Plasma, IEEE Industry Applications Society Annual Meeting, 2009.

[6] M. Sun, W. Chen, J. Min, Measurement of Non-Thermal Plasma in Negative Discharge with Water Atomized, Asia-Pacific Power an Energy Engineering Conference, 2011.

[7] B. Sun, M. Sato, J. S. Clements, Optical study of active species produced by a pulsed streamer corona discharge in water, Journal of Electrostatics, 1997.

[8] M. Sato, T. Ohgiyama, J. Clements, Formation of chemical species and their effects on microorganisms using a pulsed high voltage discharge in water, IEEE Industry Applications Society Annual Meeting, 1994.

[9] A. Joshi, B. Locke, P. Arce, W. Finney, Formation of hydroxyl radicals, hydrogen peroxide and aqueous electrons by pulsed streamer corona discharge in aqueous solution, Journal of Hazardous Materials, 1995.

[10] B. Sun, M. Sato, A. Harano, J. Clements, Non-uniform pulse discharge-induced radical production in distilled water, Journal of Electrostatics, 1998.

[11] A. Sugiarto, T. Ohshima, Active species formation of pulsed plasma in water with ring-to-cylinder reactor type electrode, International Conference on Automation, Cognitive Science, Optics, Micro-Electro-Mechanical System, and Information Technology (ICACOMIT), 2015 